1 Universidade Federal do Sul da Bahia (UFSB) Teixeira de Freitas (BA) Brasil.

Orcid: https://orcid org/0000-0001-55598853

silier@outlook.com

2 Universidade Federal da Bahia (UFBA) - Salvador (BA), Brasil.

Orcid: https://orcid

org/0000-0001-7340-

3132

maria.lirangel@gmail.com

\section{Discurso jurídico-moral e saúde nas notícias sobre o programa Crack, é Possível Vencer}

\author{
Legal-moral discourse and health in the news on the program Crack, \\ it's Possible to Win
}

Silier Andrade Cardoso Borges ${ }^{\mathbf{1}}$, Maria Ligia Rangel Santos $\mathbf{2}$

DOI: $10.1590 / 0103-1104201811907$

RESUMO O estudo objetivou investigar os enquadramentos noticiosos sobre o programa Crack, é Possível Vencer publicados nos principais veículos de comunicação da mídia impressa baiana entre dezembro de 2011 e dezembro de 2014. Buscou-se analisar as disputas entre os diferentes projetos na política de drogas no Brasil, entendendo que tais disputas de poder são atravessadas pela midiatização. Considerando-se que os enquadramentos da mídia são modos de interpretação socialmente compartilhados, a análise das notícias identificou os quadros Jurídico-Moral, Político-Econômico, Política de Saúde e Biomédico. Observou-se a predominância do quadro Jurídico-Moral, que define o crack como problema de justiça e segurança, expresso por meio da culpabilização dos usuários pelos males sociais. Embora minoritário, o quadro Política de Saúde desponta como importante contraponto, evidenciando tensões que conformam o campo. Espera-se, com a pesquisa, subsidiar investigações que se dediquem a analisar os modos de apropriação dos discursos da mídia sobre o crack pelos profissionais responsáveis pelo cuidado.

PALAVRAS-CHAVE Política de saúde. Crack. Notícias.

\begin{abstract}
The study has the objective of investigating the news frames on the program Crack, it's Possible to Win published in the main printed media in Bahia, between December 2011 and December 2014. The aim is to analyze the disputes between the different projects in the drug policies in Brazil, understanding that such power disputes are crossed by the media coverage. Considering the fact that the media frames are means of socially shared interpretation, the analyses of the news identified Legal-Moral, Political-Economic, Health Policy and Biomedical frames, that define crack as a legal and safety issue, expressed by blaming the users for social ills. Despite being a minority, the Health Policy frame emerges as an important counterpoint evidencing the tensions that shape the field. The expectations of the research are to support investigations dedicated to the analysis of the means of appropriation of discourses of the media on crack by professionals responsible for healthcare.
\end{abstract}

KEYWORDS Health policy. Crack. News. 


\section{Introdução}

O programa Crack, é Possível Vencer é uma iniciativa do Ministério da Justiça, em articulação com os demais ministérios, que propõe ações nos eixos prevenção, cuidado e autoridade. $\mathrm{O}$ eixo prevenção busca ampliar os fatores de proteção, por meio da qualificação de profissionais que integram a rede de atenção aos usuários de crack. $\mathrm{O}$ eixo cuidado busca consolidar a rede de atenção para o atendimento integral às necessidades dos usuários de drogas e seus familiares, ampliando as estratégias de enfrentamento e de reabilitação. $\mathrm{O}$ eixo autoridade destina-se à repressão policial da comercialização das drogas'.

Segundo Worm² ${ }^{2}$ trata-se de um programa concebido como estratégia que visa ofertar resposta contra um novo inimigo, produzido a partir da publicização constante nos veículos de comunicação das cenas de uso em espaços públicos (os 'fluxos') chamados de 'cracolândias'.

Os dados disponíveis sobre substâncias psicoativas apontam que as drogas lícitas se constituem em grave problema de saúde no Brasil. A Pesquisa Nacional sobre o Uso do Crack estima que apenas $0,54 \%$ dos indivíduos residentes nas capitais brasileiras fazem uso regular de $\mathrm{crack}^{3}$. No processo de implementação das políticas, houve a passagem de uma preocupação que circulava no entorno do cuidado integral aos usuários de álcool para o combate à produção, circulação e consumo crack. A passagem do cuidado à repressão evidenciou as disputas de poder e os interesses entre movimentos políticos e instituições privadas no entorno das políticas de drogas ${ }^{4}$.

Volcov e Vasconcellos 5 problematizam o uso das peças publicitárias produzidas para o programa Crack, é Possível Vencer. De acordo com as autoras, a imprensa brasileira apresenta o usuário como dependente que requer um controle heteronormativo, pois se trataria de doente mental desprovido de força de vontade e moralmente condenável.

Segundo Cheibub6, a midiatização do crack atende a anseios de exclusão dos desviantes e os associa entre droga, crime e doença, buscando legitimar o recrudescimento do controle dos desviantes por meio dos sistemas de saúde e penitenciário.

Cabe aqui compreender midiatização da sociedade, nos termos de Hjarvard ${ }^{7}$, como o processo pelo qual a sociedade torna-se cada vez mais submetida à lógica da mídia. Trata-se de um processo em que, ao mesmo tempo que os meios de comunicação passaram a estar cada vez mais integrados às outras instituições, passaram também a adquirir status de instituição social, de modo que as interações passaram a ocorrer mediadas pelos meios de comunicação.

Neste artigo, a midiatização do crack é entendida como os mecanismos pelos quais o modo como se organizam as políticas de drogas, as representações sobre os modos de uso e os usuários do crack - bem como os meios e os responsáveis pela sua assistência, cuidado ou repressão - são, em parte, influenciados pela produção e circulação midiática desses bens simbólicos, por meio de peças publicitárias, notícias etc. As notícias não apenas transmitem informação, mas também participam da construção da realidade social e afetam as práticas e os discursos, produzindo efeitos de sentido e subjetividades ${ }^{\mathbf{8}, 9}$.

Partindo da premissa de que os enquadramentos da mídia são modos de interpretação da realidade socialmente compartilhados, o estudo objetiva investigar os enquadramentos noticiosos sobre o programa Crack, é Possível Vencer publicados nos principais veículos de comunicação da mídia impressa baiana entre dezembro de 2011 e dezembro de 2014. Busca-se analisar as disputas entre os diferentes projetos na política de drogas no Brasil, entendendo-se que tais disputas de poder são atravessadas pela midiatização.

\section{Métodos}

A primeira etapa do estudo consistiu na seleção de notícias veiculadas na mídia impressa pelos dois jornais de maior circulação 
no estado da Bahia, entre dezembro de 2011 e dezembro de 2014.

O período de coleta foi escolhido tendo como parâmetro a data de lançamento do referido programa. O levantamento das notícias impressas publicadas no jornal 'A Tarde' se deu mediante a busca pela palavra-chave 'crack, é possível', por intermédio de software disponibilizado na sede da referida empresa, em 13 de outubro de 2015. O levantamento das notícias impressas publicadas pelo jornal 'Correio da Bahia' ocorreu na sede da Rede Bahia em 23 de outubro de 2015. Buscou-se atender aos critérios de exaustividade, representatividade, homogeneidade e pertinência na seleção das notícias. Com base na palavra-chave, foram retornadas na busca 14 notícias veiculadas pelo 'A Tarde' e 9 notícias publicadas pelo jornal 'Correio', totalizando 23 notícias. Destas, foram selecionadas apenas 9 notícias do jornal 'A Tarde' e 4 notícias do jornal 'Correio', totalizando 13 notícias. Dez notícias foram excluídas de acordo com os seguintes critérios: apenas citam o programa, sem discuti-lo ou abordá-lo diretamente; notícias publicadas nos campos de opinião; notícias publicadas no espaço do leitor. Tais exclusões ocorreram porque as notícias dos campos de opinião e espaço do leitor são geralmente acompanhadas de avisos de que tais publicações não traduzem a opinião do jornal, mas somente dos autores dos textos.

Identificados o ano, o mês e a página de publicação, procedeu-se à cópia das notícias, disponibilizadas pela Biblioteca Pública do Estado da Bahia.

A segunda etapa envolveu a Análise do Enquadramento das notícias selecionadas. $\mathrm{O}$ método de produção dos dados envolveu a identificação de palavras e expressões recorrentes, bem como padrões persistentes e estereotipias nos textos e nos recursos gráficos levantados, sem apartar essa etapa da análise da interlocução dos bens simbólicos produzidos pelos sistemas de mídia e os elementos políticos, jurídicos e culturais que circulam no entorno da discussão sobre o crack. Adotouse a abordagem dedutiva, que possibilita a emergência dos quadros por meio da categorização das notícias após análise exaustiva do material, subsidiada na revisão de literatura sobre midiatização do crack e o percurso das políticas de drogas no Brasil.

A noção de enquadramento framing se apresenta como conceito promissor para a compreensão das relações tecidas entre jornalismo e os atores sociais da saúde. Os frames seriam produzidos a partir das relações estabelecidas entre a mídia e o campo da saúde, compreendidos como campos indissociáveis do universo social e simbólico, em constantes disputas de poder e de sentido sobre o processo saúde-doença-cuidado. Os sistemas de mídia funcionam também como atores sociais que não apenas espelham a realidade, mas que também participam da sua construção operando narrativas sobre o mundo. Os frames são identificados pelos critérios de seleção e saliência, em que aspectos da realidade são selecionados e tornados mais salientes no corpo de um texto comunicativo ${ }^{10,11}$.

\section{Resultados e discussão}

Foram identificados os quadros: JurídicoMoral, Política de Saúde, Político-Econômico e Biomédico, sintetizados no quadro 1. Os dados levantados indicam a ocorrência de 35 declarações ou registros do quadro JurídicoMoral, hegemônico nas notícias que abordam o programa Crack, é Possível Vencer nos veículos de comunicação investigados. Por sua vez, o quadro Política de Saúde apresentou 29 ocorrências, indicando importante tensão entre estas devido ao antagonismo presente nos diferentes projetos políticos e nas diferentes formas de compreender a droga e os usuários, subjacentes aos quadros. O quadro Político-Econômico apresentou 25 ocorrências, enquanto que o Biomédico apresentou apenas 8. 
Quadro 1. Enquadramento das notícias sobre o programa Crack, é Possível Vencer

\begin{tabular}{|c|c|c|c|}
\hline QUADROS & DESCRIC̣ÃO & $\begin{array}{l}\text { DISPOSITIVO DE } \\
\text { ENQUADRAMENTO }\end{array}$ & DISPOSITIVO DE RACIOCÍNIO \\
\hline $\begin{array}{l}\text { Jurídico- } \\
\text {-Moral }\end{array}$ & $\begin{array}{l}\text { O crack como pro- } \\
\text { blema de justiça e de } \\
\text { segurança pública. }\end{array}$ & $\begin{array}{l}\text { Palavras, expressões como 'com- } \\
\text { bate ao crack', 'combate ao uso de } \\
\text { droga', 'combate ao tráfico', 'ação } \\
\text { contra o crack', 'na mira do progra- } \\
\text { ma', 'cracolândia', 'monitoramento } \\
\text { por câmeras', 'repressão sem } \\
\text { complacência', 'é possível vencer o } \\
\text { problema'. } \\
\text { Imagens que retratam o aprisiona- } \\
\text { mento de usuários, cenas de uso } \\
\text { do crack que associam a droga à } \\
\text { 'sedução' e ao 'mal'. }\end{array}$ & $\begin{array}{l}\text { Compreende o crack como problema } \\
\text { em si; argumentos de caráter jurídico } \\
\text { e repressor; o consumo do crack como } \\
\text { problema de segurança pública; associa } \\
\text { criminalidade e violência ao consumo, } \\
\text { responsabilizando o indivíduo pelos males } \\
\text { sociais; usuário como objeto de interven- } \\
\text { ção policial e religiosa; centralidade do uso } \\
\text { de armas; a internação compulsória como } \\
\text { medida resolutiva e prioritária do Estado. }\end{array}$ \\
\hline $\begin{array}{l}\text { Política de } \\
\text { Saúde }\end{array}$ & $\begin{array}{l}\text { Uso do crack como } \\
\text { fenômeno de deter- } \\
\text { minações sociais, } \\
\text { econômicas e psicoló- } \\
\text { gicas, definindo-se as } \\
\text { estratégias de acompa- } \\
\text { nhamento em rede de } \\
\text { serviços substitutivos. }\end{array}$ & $\begin{array}{l}\text { Palavras e expressões como } \\
\text { 'consultórios de rua', 'psicólogos', } \\
\text { 'lideranças locais', 'equipe multi- } \\
\text { profissional', 'redução de danos', } \\
\text { 'humanizado', 'sofrimento psíqui- } \\
\text { co', 'vínculo de confiança', 'aten- } \\
\text { dimento psicossocial', 'proteger a } \\
\text { vida', 'projeto de vida'. }\end{array}$ & $\begin{array}{l}\text { Aponta para o uso do crack como objeto } \\
\text { de enfoque na rede de serviços de saúde } \\
\text { e dos dispositivos que integram a rede in- } \\
\text { tersetorial; destaca a promoção da saúde, } \\
\text { de vida e de cidadania como princípios da } \\
\text { intervenção de caráter psicossocial, rea- } \\
\text { lizado em serviços territoriais por equipe } \\
\text { multiprofissional. }\end{array}$ \\
\hline $\begin{array}{l}\text { Político- } \\
\text { Econômico }\end{array}$ & $\begin{array}{l}\text { O crack como objeto } \\
\text { de intervenção política } \\
\text { por meio da captação e } \\
\text { destinação de recursos } \\
\text { públicos. }\end{array}$ & $\begin{array}{l}\text { Palavras e expressões como 'ter- } \\
\text { mo de adesão', 'investimento no } \\
\text { programa', 'R\$ } 4 \text { bilhões da União', } \\
\text { 'convênio com o Ministério da } \\
\text { Justiça', 'convênio com a União', } \\
\text { 'recurso será investido'. }\end{array}$ & $\begin{array}{l}\text { Adesão dos Estados e Municípios ao pro- } \\
\text { grama; são apresentadas as estratégias de } \\
\text { implementação, considerando seus eixos } \\
\text { norteadores; ênfase na discussão sobre os } \\
\text { custos e os recursos públicos destinados } \\
\text { ao enfrentamento do crack. }\end{array}$ \\
\hline Biomédico & $\begin{array}{l}\text { O uso do crack como } \\
\text { doença e o usuário } \\
\text { como indivíduo avoli- } \\
\text { tivo, objeto do saber e } \\
\text { poder médico. }\end{array}$ & $\begin{array}{l}\text { Palavras e expressões como 'tra- } \\
\text { tamento de viciados', 'dependente } \\
\text { químico', 'epidemia de crack', } \\
\text { 'comunidade médica', 'risco à pró- } \\
\text { pria vida', 'sinais de intoxicação', } \\
\text { 'diagnosticado'. }\end{array}$ & $\begin{array}{l}\text { O problema do crack como decorrente } \\
\text { de desordens neuromédicas, legitiman- } \\
\text { do a internação involuntária; Perspectiva } \\
\text { médico-centrada, em que o crack é con- } \\
\text { siderado problema de saúde, de caráter } \\
\text { epidêmico, comparado à Aids. }\end{array}$ \\
\hline
\end{tabular}

Fonte: Elaboração própria.

\section{O quadro Jurídico-Moral: a política proibicionista e a culpabilização dos usuários}

\author{
A análise do enquadramento das notícias \\ aponta para a presença persistente do quadro \\ Jurídico-Moral e reflete sentidos partilhados \\ socialmente, em que o crack consiste em um \\ problema em si mesmo, entidade autônoma \\ deslocada da história, cabendo como estra- \\ tégia de sua resolução a implementação de \\ ações de 'combate ao crack' por meio da força \\ repressora do Estado.
}

A hegemonia do quadro Jurídico-Moral aponta para o crack como problema de polícia. A partir de uma perspectiva moralizante, vê-se o consumo como fomentador do tráfico e reprodutor da violência; e sendo o principal responsável pelas mazelas coletivamente compartilhadas. Caberia ao Poder Judiciário, sob a égide do Código Penal, intervir sobre a liberdade do consumidor, de modo a assegurar o ordenamento social.

O quadro Jurídico-Moral indica como as notícias atendem aos anseios culturais por segregação dos usuários de crack, por meio de 
discursos que associam a droga à criminalidade e à violência que, produzidos e circulados como bens simbólicos pelos veículos de comunicação, resultam no fenômeno da midiatização do crack. Para Volcov e Vasconcellos 5 , é por meio da mídia que se tem colocado em pauta o uso das drogas como problema de segurança ou de saúde pública.

Os dispositivos de enquadramento mais presentes indicavam expressões que remetem aos mecanismos sociais de controle, como 'monitoramento por câmeras', 'repressão sem complacência', 'ação contra o crack', 'combate ao tráfico' e 'é possível vencer o problema'. Trata-se de palavras que remetem ao paradigma proibicionista de guerra às drogas, que reduz a assistência ao viés moral, dissociada das diferentes trajetórias de vida e das experiências de sofrimento das pessoas que realizam uso de drogas. Embora o quadro JurídicoMoral seja hegemônico na notícia 'Arma de choque será usada contra viciados', por meio do uso reiterado de certas expressões, jargões e imagens, fazem-se presentes outras vozes, que apontam para a repressão do consumo como objeto de controvérsia entre os quadros Jurídico-Moral e Política de Saúde:

CRACK: As polícias do Brasil terão armas de choque e spray de pimenta para conter dependentes de crack. A distribuição desses dispositivos é uma das ações previstas no programa 'Crack, é Possível Vencer', do Ministério da Justiça. A utilização de força policial, incluindo armas não letais, para o controle de dependentes é controversa. Em São Paulo, operação iniciada em janeiro por estado e prefeitura foi criticada por especialistas, que defendiam foco maior em saúde ${ }^{\mathbf{1 2 ( 5 )}}$.

As imagens também reforçam o quadro Jurídico-Moral. Consistem em imagens fotográficas ou charges que utilizam de maneira recorrente a função emotiva, com o retrato de jovens negros, vestidos com trapos, em cenas de uso em via pública. Há, também, imagens em que jovens são carregados e enviados para internação compulsória por agentes da
Secretaria de Assistência Social do Rio de Janeiro. A charge veiculada reitera o título da notícia 'internação involuntária para enfrentar o crack', apresentando o desenho de um jovem negro e magro, hipnotizado por um objeto misto de cachimbo e de serpente.

Os achados coadunam com o estudo de Souza e Oliveira ${ }^{13}$, que se dedicaram a análise de reportagens divulgadas em um jornal impresso de Salvador sobre o fenômeno das drogas. De maneira semelhante, as autoras confirmaram o enfoque reducionista das drogas pela mídia impressa, vinculação das drogas à violência e divulgação de representações estereotipadas do usuário, centrado no homem negro e residente em bairros periféricos.

Embora houvesse, nas notícias, diferentes entrevistados, não houve assimetria entre os falantes, de modo que as notícias privilegiaram a fala dominante das fontes oficiais. Em apenas uma notícia, os jornalistas optaram por entrevistar transeuntes e moradores do bairro da Barra, região nobre de Salvador, apresentando suas opiniões sobre a contribuição do programa. Os relatos apontam para a necessidade de garantia do ordenamento e da paz pública por meio da internação involuntária dos usuários, responsabilizados pelo aumento da criminalidade; e, secundariamente, avaliam os benefícios do programa com o tratamento da dependência, compreendida enquanto 'vício'.

Quem mora na Barra ou apenas frequenta o local, a exemplo da consultora de vendas [...], 34 anos, vê a iniciativa como necessária. Ela observa que 'tudo que vier para garantir uma maior segurança da população e, por consequência, tratar o vício das drogas, sempre será bem-vindo'. Por sua vez, o vendedor de água de coco [...] de 48 anos, avalia a adesão ao programa 'Crack, é Possível Vencer' como 'importante' porque, segundo espera, deve trazer mais tranquilidade a moradores e frequentadores da barra. 'O crack está acabando com as pessoas, que acabam cometendo pequenos furtos para sustentar o vício, como já

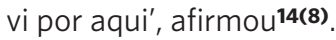


Depoimentos de usuários são evocados para coadunar com o paradigma proibicionista, tornando tênue a linha que separa o quadro Jurídico-Moral do quadro Biomédico. As experiências pessoais são suscitadas nas narrativas tão somente para coadunar com a responsabilização dos sujeitos pelas circunstâncias da vida e pelas condições inadequadas de moradia às quais estão submetidos. As drogas aparecem como substâncias dotadas de poderes próprios, e os sujeitos, desprovidos de protagonismo, descrevem-se incapazes de compreendê-las ou de ofertar resistência a elas diante de seu potencial de sedução:

Eu morava e trabalhava em Salvador, conheci uma mulher e passei a fumar crack. Quando fui ver, havia perdido o trabalho e já morava na rua. [...] Já o lavador de carros E.A.J., 27, três filhos, hoje na Casa do Alabrastro, morava em Salvador e pretendia ir trabalhar em São Paulo. Nem sei dizer bem o que ocorreu, só sei que não deu certo e quando abri os olhos, já morava nas ruas. Estou nessa há quatro anos. Mas acho que agora vou conseguir sair, apostou15(4).

Em oposição à perspectiva jurídico-moral, que tipifica o consumidor como força poderosa que corrompe sujeitos moralmente fracos, a perspectiva ética resgata a heterogeneidade social e cultural dos usuários, em que se diferenciam as trajetórias de vida, a renda, a etnia e a classe social, as formas de consumo, os espaços em que se realizam os diferentes modos de uso, bem como as diferenças na composição química das substâncias consumidas nesses espaços, aspectos estes que se relacionam com os modos pelos quais o mercado ilegal regula as relações de consumo, isto é, como se distinguem os consumidores conforme seus gostos e seu potencial aquisitivo na busca de produtos a partir de critérios como preço, qualidade e sofisticação ${ }^{16}$.

Considerando-se os achados, é possível afirmar que o quadro Jurídico-Moral aponta para um conjunto de estratégias discursivas e imagéticas de natureza ideológica adotadas nas notícias, que, por um lado, tornam salientes a naturalização do crack como avassalador, violento e viciante 'craving' e a substância como inimigo público e que, por outro, oculta, exclui ou secundariza o papel da rede substitutiva na garantia de direitos, produzindo bens simbólicos que coadunam com a política da repressão em detrimento das políticas de promoção da saúde.

\section{O quadro Política de Saúde: promo- ção de saúde e cidadania a partir de estratégias reabilitadoras}

Em oposição ao quadro Jurídico-Moral, o quadro Política de Saúde define o usuário de crack como objeto de enfoque na rede de serviços de saúde e nos dispositivos que integram a rede intersetorial, sobretudo nos serviços que integram a Assistência Social, Educação e Cultura. O enquadre da Política de Saúde destaca a promoção da saúde, da vida e da cidadania como princípios éticos, realizados na Rede de Atenção Psicossocial (Raps), conjunto articulado de serviços territoriais que exercem o cuidado em saúde mental por meio de equipes multiprofissionais e estratégias sociocomunitárias.

Como referência às estratégias de reabilitação adotadas no âmbito das políticas de saúde mental, que envolvem a reconstrução do direito à cidadania, ao trabalho e à palavra a partir de encontros afetivos como fundamentos do ato terapêutico, o quadro Política de Saúde se manifesta nas notícias por meio de dispositivos de enquadramento como 'atendimento psicossocial', 'projeto de vida', 'rede de atendimento', 'proteger a vida', 'vínculo de confiança', bem como referência a serviços como 'Centros de Atenção Psicossocial', 'Consultórios de Rua', entre outros.

O depoimento de Alexandre Padilha, até então Ministro da Saúde, destacado na notícia, ilustra como o quadro Política de Saúde seleciona elementos que coadunam com uma complexa rede de cuidados aos usuários de crack, salientando a defesa ao direito à saúde 
e à vida, que não se esgota a atenção integral por meio de dispositivos públicos, mas que reconhece o papel da construção terapêutica de novos modos de existência, em consonância com o paradigma da Reabilitação Psicossocial:

Temos que oferecer um novo projeto de vida ao dependente químico porque a relação com a droga tem relação com o lugar onde ele vive, com o espaço social, a sua condição na família. Isso exige serviços de saúde diferentes para necessidades diferentes, afirmou o ministro da Saúde, Alexandre Padilha17(7).

O quadro Política de Saúde, em oposição ao quadro Jurídico-Moral, aponta para as tensões entre os diferentes projetos sobre as políticas de drogas que, devido ao jogo de forças e de interesses, alternam-se entre propostas políticas que, de um lado, coadunam com o paradigma proibicionista de guerra às drogas e, de outro, por políticas sociais que objetivam a produção de cidadania, saúde e cuidado territorial aos usuários e seus familiares.

Cabe, contudo, mencionar que o cenário contemporâneo aponta para certo recrudescimento de políticas de drogas proibicionistas no Brasil, ao tempo que países como Portugal, Holanda, Finlândia, Uruguai e Espanha caminham na contramão do proibicionismo e seus efeitos, como a abusividade das abordagens policiais, o sucateamento das políticas de saúde, o encarceramento em massa e as violações de direitos humanos ${ }^{\mathbf{1 8}}$.

No campo das políticas de saúde, observa-se que esses tensionamentos se expressam por meio do lobby realizado por representantes das Comunidades Terapêuticas (CT), que realizaram intenso processo de institucionalização desses dispositivos privados que recebem repasses públicos para promover a exclusão dos usuários de drogas do seu convívio social e familiar, legitimando-se ao tempo em que resgatam a mesma e velha lógica privatista e manicomial ${ }^{19}$. Tais instituições, em sua maioria vinculadas a organizações evangélicas, mesmo com recorrentes denúncias de violação de direitos, vêm obtendo sucessivos êxitos no legislativo.

Tensionamentos semelhantes podem ser identificados, de um lado, no Plano Integrado de Enfrentamento ao $\mathrm{Crack}^{\mathbf{2 0}}$ e pelo programa Crack, é Possível Vencer, orientados pelo modelo de campanhísmo anticrack; e, de outro, pela Política do Ministério da Saúde pela Atenção Integral aos Usuários de Álcool e Outras Drogas ${ }^{21}$, que exige novas estratégias de contato e vínculo entre profissional, usuário e familiares, orientada pela redução de danos e segundo as diferentes necessidades dos envolvidos.

\section{O quadro Político-Econômico: o enfrentamento ao crack como gasto público}

O quadro Político-Econômico define o crack como objeto de intervenção política por meio da captação e destinação de recursos públicos do programa Crack, é Possível Vencer entre os poderes do executivo federal, estadual e municipal. Assim, o crack torna-se um problema econômico, que envolve negociações políticas pela captação dos repasses e se caracteriza pela adoção de medidas administrativas e burocráticas. Nesse sentido, as notícias que se situam no quadro Político-Econômico secundarizam as experiências dos usuários, excluem do plano de análise as lutas políticas que se dão na esfera pública, restringindo-se à simplificação da problemática do consumo à questão de investimentos financeiros centralizados pelo Governo Federal e distribuídos aos estados e municípios.

As notícias que expressam o quadro Político-Econômico se reduzem à seleção de elementos textuais e imagéticos que se referem aos montantes destinados aos aparatos de repressão do Estado, como a compra de videomonitoramento das 'cracolândias' e a aquisição de veículos de segurança e investimentos no treinamento de policiais, denotando interfaces entre o quadro Político-Econômico e o Jurídico-Moral. Eventualmente, o programa é anunciado ora como investimento, ora como 
despesa que onera o contribuinte, e a ação política é apresentada como constrangida pela campanha eleitoral e por interesses de ordem político-partidária.

\section{0 quadro Biomédico: o consumo como doença e a epidemia do crack}

O quadro Biomédico aparece como minoritário entre os demais. O quadro é expresso nas notícias por meio de palavras e expressões 'tratamento de viciados', 'dependente químico', 'epidemia de crack', 'comunidade médica', 'risco à própria vida', 'sinais de intoxicação', 'diagnosticado'. Como dispositivo de raciocínio, esse enquadre define o problema do consumo do crack como decorrente de desordens genéticas, clínicas ou neuromédicas, legitimando a internação involuntária do sujeito doente, simultaneamente transgressor e avolitivo. Trata-se de uma perspectiva centrada na figura do médico, na qual o crack é considerado como doença ou epidemia, comparado à Aids:

Epidemia: o ministro da Saúde, Alexandre Padilha, comparou o momento atual no combate à droga à epidemia de Aids no início da década de 80, quando a comunidade médica se viu diante de questionamentos éticos e de como atuar para resolver o problema. Na visão de Padilha, a Aids agora está sob controle e a saúde encontrou uma forma de atuação. Isso, segundo acredita, deve se repetir com o crack. O crack tem a mesma dimensão deste desafio. No conceito técnico, estamos, sim, diante de uma epidemia de crack em nosso país, disse o ministro22(6).

O quadro Biomédico aponta para o modelo sanitário campanhísta por meio da divulgação de informações com forte apelo emocional que indicam os riscos de dependência desde o primeiro consumo.

Para Cunda e Silva ${ }^{23}$, o campanhísmo anticrack é subsidiado na culpabilização do indivíduo e da família pelo consumo do crack. Esse modelo campanhísta se apresenta em notícias que exigem do poder público a internação em massa dos usuários, definidos como doentes mentais ou dependentes químicos, e ampara seu discurso publicitário nas neurociências, que reivindicam a fatalidade da alteração neuronal ou do circuito de recompensa cerebral, à iminência da morte perante o uso, no levantamento de fatores de risco para o envolvimento, às heranças genéticas da dependência e ao suposto deficit cognitivo resultante do consumo regular.

O fato de o quadro Biomédico aparecer como minoritário entre os demais pode estar relacionado com aquilo que Madel Luz ${ }^{\mathbf{2 4}}$ chama de 'crise do saber médico', que não se refere à crise da medicina enquanto campo produtor de conhecimento, mas à crise de sua própria racionalidade, compreendida enquanto sistema de saber complexo e estruturado. Essa crise se caracterizaria pelo afastamento da medicina do sujeito em sofrimento enquanto totalidade, descentrado enquanto objeto de investigação e objetivo da prática terapêutica para dar lugar à doença, acompanhada da desmesurada ênfase no diagnóstico e em tecnologias predatórias e iatrogênicas em lugar da medicina enquanto arte de curar.

Carl Hart ${ }^{25}$, em sua vinda ao Brasil, visitou a favela da Maré no Rio de Janeiro e foi alertado de que encontraria cracolândias repletas de 'zumbis' movidos pelo desejo incontrolável de obter mais uma 'pedra'. Todavia não presenciou apenas brigas e uso de crack em cachimbos improvisados, mas narrativas sobre violência policial, desemprego, pobreza, sonhos e projetos de vida. Talvez o desafio seja seguir nos caminhos do Gey Espinheira ${ }^{16}$ e observar que os distintos modos de se relacionar com a droga se localizam na busca pelo sentido da existência, contudo sem dissociar tal busca da constatação de que vivemos uma sociedade modular, paradoxalmente da superabundância e da escassez, mas também do espetáculo, da insegurança, do medo e da desestabilização do trabalho. Por essa razão, ainda se faz necessário ressaltar que 'slogans 
vazios, com suas rimas cativantes, são excelentes para animar os desinformados, mas eles também escondem os verdadeiros problemas e obstruem nossa capacidade de implementar soluções adequadas'.

\section{Considerações finais}

Os enquadramentos das notícias privilegiam o entendimento do programa a partir da culpabilização jurídico-moral dos usuários pelo uso, responsabilizando-os por consequências sociais que transcendem à esfera do consumo, ao mesmo tempo que se fazem presentes quadros que salientam o papel das políticas públicas na produção de saúde e de cidadania dos usuários do crack.

A experiência humana é significada por meio de processos comunicacionais e

\section{Referências}

1. Brasil. Ministério da Justiça. Cartilha crack, é possível vencer. Enfrentar o crack, compromisso de todos. Brasília, DF: Ministério da Justiça; 2013.

2. Worm N. Políticas públicas de drogas: estudo do programa crack, é possível vencer e as estratégias para uma política nacional [tese]. São Paulo: Universidade Presbiteriana Mackenzie; 2016. 228 p.

3. Bastos FI, Bertoni N. Pesquisa Nacional sobre o uso de crack: quem são os usuários de crack e/ou similares do Brasil? Quantos são nas capitais brasileiras? tecnológicos que caracterizam a sociedade midiatizada. Não caberia compreender as notícias sobre o crack como espelhos da realidade, mas buscar identificar sob quais condições se produzem e circulam bens simbólicos sobre os modos de lidar com a droga, isto é, quais os tensionamentos políticos, as inconsistências, as estratégias de poder e de produção de sentidos que são selecionadas, salientadas ou eliminadas nos discursos jornalísticos.

\section{Colaboradores}

Todos os autores contribuíram para a concepção, o planejamento, a análise e a interpretação dos dados; para a elaboração do texto e revisão crítica do conteúdo; e participaram da aprovação da versão final do manuscrito.
Rio de Janeiro: Icict/Fiocruz; 2014.

4 lise do enquadramento da saúde em programas da série de TV Ser Saudável-TV Brasil [tese]. Salvador: Universidade Federal da Bahia; 2015. 260 p.

5. Volcov K, Vasconcellos MP. 'Crack, é Possível Vencer' ou é possível compreender: observações a partir de campanhas publicitárias do governo federal. Saúde Transform Soc. 2013; 4(2):99-105. 
6. Cheibub WB. Práticas disciplinares e uso de drogas: a gestão dos ilegalismos na cena contemporânea. Psic Cienc Prof. 2006; 26(4):548-557.

7. Hjarvard S. Midiatização: teorizando a mídia como agente de mudança social e cultural. Matrizes. 2012; 8(2):53-91.

8. Fausto Neto A. Fragmentos de uma analítica da midiatização. Matrizes. 2008; 1(2):89-105.

9. Barros LM. Recepção, mediação e mediatização: conexão entre teorias europeias e latino-americanas. In: Junior JJ, Mattos MA, Jacks N, organizadores. Mediação \& midiatização. Salvador: EDUFBA; 2012.

10. Gonçalves T. A abordagem do enquadramento nos estudos do jornalismo. Caleidoscópio Rev Comunic Cult. 2011; 5(6):157-167.

11. Carvalho CA. Sobre limites e possibilidades do conceito de enquadramento jornalístico. Contemporanea Rev Comunic e Cult. 2010; 7(2):1-15.

12. Arma de choque será usada contra viciados. Jornal A Tarde. 2012 nov 15. Cad. 1:5 (col.1).

13. Souza MRR, Oliveira JF. Fenômeno das drogas: análise de reportagens veiculadas em um jornal de salvador. Rev Baiana Enferm. 2008; 22(1-3):145-56.

14. Polícia propõe uma ação anticrack mais humanizada. Jornal A Tarde. 2014 out 2. Cad. 1:8 (col.1).

15. Programa busca reabilitar dependentes químicos. Jornal A Tarde. 2014 jan 21. Cad. 1:4 (col.2).

16. Espinheira G. Os tempos e os espaços das drogas. In: Almeida AR, Ferreira OS, Macrae E, et al, organizadores. Drogas, tempos, lugares e olhares sobre o seu consumo. Salvador: EDUFBA; 2004.
17. Governo federal reforçará a rede de atenção local. Jornal A Tarde. 2011 dez 10. Cad. 1:7 (col.3).

18. Custódio R. ONG e política de drogas: um olhar sobre as estratégias de combate ao proibicionismo. Rev Sur; 2015; 12(21):1-4.

19. Tófoli LF. Políticas de drogas e saúde pública. Rev Sur. 2015; 12(21):1-4.

20. Brasil. Decreto ${ }^{\circ} 7.179$, de 20 de maio de 2010. Institui o Plano Integrado de Enfrentamento ao Crack e outras drogas, cria o seu comitê gestor, e dá outras providências. Diário Oficial da União. 21 Maio 2010.

21. Brasil. Ministério da Saúde. A Política do Ministério da Saúde para atenção integral a usuários de álcool e outras drogas. Brasília, DF: Ministério da Saúde; 2003.

22. Dilma lança pacote de $\mathrm{R} \$ 4$ bilhões contra o crack. Jornal A Tarde. 2011 dez 8. Cad. 1:6 (col.1).

23. Cunda MF, Silva RAN. O crack em um cenário empedrado: articulações entre o discurso jurídico, médico e midiático. Psicol Soc. 2014; 26(esp):245-255.

24. Luz MT. Novos saberes e práticas em Saúde Coletiva: estudos sobre racionalidades médicas e atividades corporais. 3. ed. São Paulo: Hucitec; 2012.

25. Hart CL. Slogans vazios, problemas reais. Rev Sur. 2015; 12(1):1-4.

\section{Recebido em 15/07/2018 \\ Acesso em 25/11/2018 \\ Conflito de interesses: inexistente}

Suporte financeiro: não houve 